\title{
A STUDY ON POLYSTYRENE-METAL POWDER CONDUCTIVE COMPOSITES
}

\author{
M. Z. Iqbal", G. M. Mamoor, Tariq Bashir, M. S. Irfan, M. B. Manzoor \\ Department of Polymer and Process Engineering, University of Engineering and Technology Lahore- \\ Pakistan
}

\begin{abstract}
Conductive polymer composites were prepared from polystyrene as the base material and utilizing different metallic fillers by melt processing technique using a Brabender ${ }^{\circledR}$ plasticorder at $230^{\circ} \mathrm{C}$ and 120 RPM spindle speed. Different fillers used include nickel powder, carbon black, Iron and copper powders of one micron sizes. Samples for tensile, thermal and resistivity testing were prepared from hydraulic press under 220 bar pressure, at $220^{\circ} \mathrm{C}$ for 5 minutes and then cooling to atmospheric temperature. Iron based polystyrene composite showed good mechanical properties and nickel based composite showed better thermal and conductive properties. Three kinds of treating agents were used to modify iron which includes wax, stearic acid and acetic acid. Iron treated with acetic acid composites showed improvement in electrical and mechanical properties. This improvement was attributed to the chemical linkage established between acetic acid and polystyrene at the processing temperatures.
\end{abstract}

\section{Keywords}

conductive composite; fillers; polystyrene; metal

\section{Introduction}

Combination of thermoplastic polymers and metallic fillers constitute a major group of engineering materials employed in widely diversified fields, e.g, discharging static electricity[1], heat conduction, gas storage[2] and electromagnetic shielding[3-4] etc. Commodity thermoplastics have been reported to exhibit good properties when filled with metallic powders, e.g, polyethylene[5-9], polypropylene[10-12]. Conductivity of the polymer composites containing dispersed conductive fillers depends on many factors such as the size and shape of the filler particles, their spatial distribution within a polymer matrix, the interactions between the filler surface and the polymer matrix, and the contact resistance between adjacent particles [1315]. All these factors determine the conditions of charge transport from one particle to another, i.e., the conductivity of the filler phase. Chemically modified fillers[16-18] have also been reported to improve different properties of conductive composites.

In the present study, we report the dependence of conductivity of metal-polymer composites where nickel, aluminum, zinc oxide, iron and carbon black are used as dispersed conductive fillers in polystyrene. Mechanical, thermal and electrical properties were measured as a function of filler loadings. Iron powder was treated afterwards with wax, stearic and acetic acids to test the effectiveness of surface treatment on the properties of

\footnotetext{
*Corresponding Author's Email : mziqbal@uet.edu.pk
}

composites. Effect of filler concentration on mechanical and thermal properties has been reported. Polystyrene is being used because it is amorphous when processed and is a very cheap material.

\section{Experimental Details}

\section{Materials}

Polystyrene (Injection grade Diamond gp. 525 Grade, manufactured by Pak Petrochemical Industries), Copper Powder (1 micron, Merck), Nickel Powder (1 micron, Merck), Iron Powder (1 micron, Merck), Activated Carbon Black (Merck). Wax (locally manufactured from market), Stearic Acid and Acetic acid (Merck) were used in this research.

\section{Composites Manufacturing}

Composite samples of polystyrene and metallic fillers

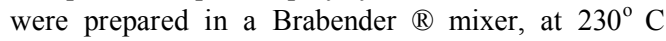
temperature and 120 RPM for four minutes (Time within which the material could sustain its properties and did not degrade during processing. This time was determined by running a number of pure polystyrene samples in the mixer at the different conditions). Sample sheets were formed by pressing (preheating for $10 \mathrm{~min}$, pressure for $5 \mathrm{~min}$ at $220^{\circ} \mathrm{C}$ and $200 \mathrm{bars}$, cooling under pressure) into 1 and $2 \mathrm{~mm}$ thick plates, from which samples were taken for physical, mechanical and thermal characteristics measurements. Composite with metallic powders concentrations 
ranging between 0 and $25 \%$ by volume have been prepared.

\section{Treatment of the filler}

Iron powder was dispersed in wax, stearic and acetic acids prior to mixing with polystyrene with the help of mechanical mixers. Table 1 shows the relative weight percentages of the treating agents. After premixing iron with treatments, mixture was dropped in Brabender working at $210^{\circ} \mathrm{C}$ and $90 \mathrm{RPM}$ for stearic acid and wax and for acetic acid treatment, temperature was kept at $220^{\circ} \mathrm{C}$ in order to see its coupling with phenyl group of polystyrene which appeared with the color change. After making composites, samples for property measurement were prepared by hot press at $220^{\circ} \mathrm{C}$ temperature and 220 bar pressure and then cooled under pressure.

\section{Property Measurements}

Tensile strength was measured by using TIRA TEST 2810 (Germany) and samples prepared for these were according to ASTM D-638. Thermal properties were determined from Melting Point Apparatus (ats faar, Italy). The conductive measurements were carried out using Tera Ohmmeter (Type 6148, CEAST, Italy).

\section{Results and Discussion}

\section{Mechanical Characterization}

\section{Tensile Properties}

Different weight percents of the fillers were employed such as 5,10,15,20,25. Figure 1 represents a comparison between the percentage of filler in the composite and ultimate tensile strength of the samples. From the figure it can be seen that as the concentration of filler increases, the force required to break the sample decreases. Iron and copper based samples showed almost the same behavior but carbon black totally differently. This is possibly due to the reason that carbon particles show break down of agglomerates with increase in breaking force and as concentration crosses a critical value with respect to matrix material concentration, there is again a uniform distribution of $\mathrm{C}$ black particles in the matrix with shear.

Effect of treating agents on the ultimate tensile strength of iron filler composites is presented in Figure 2. A maximum ultimate force was observed in all the cases while in the case of acetic acid, even a very small percentage of the treating agent marked with large tensile strength. This exceptional increase in ultimate tensile force can be attributed to the reaction between acetic acid and phenyl group of polystyrene, stated elsewhere.

\section{Conductivity Measurement}

The resistivity values were taken from teraohm meter which were then converted into the volume resistivity values by using the following equation:

$$
\square=\square \mathrm{RT}
$$

Where

$\mathrm{R}=$ volume resistance $(\square)$

$\mathrm{T}=$ thickness of disc $(\mathrm{cm})$

$\square=$ Area of circular disc $(\mathrm{cm} 2)$

Resistivity values were converted into conductivity values by taking the inverse. Figure 3 shows the comparison between the conductance values of polystyrene conductive composites having different filler loadings and effect of treating agents. It was observed that the conductivity values at the beginning were different for all the fillers but as their amount increases in the composite, they all approached to the same conductivity values. In general, conductivities increased with filler loadings. As shown previously, iron filled composites showed improved mechanical properties. Iron was treated with three different treating agents and was analyzed for electrical conductivity. Acetic acid treated composite samples showed better electrical conductivity value at lower loading showing better adhesion of particles with polymer matrix.

\section{Thermal analysis}

Melting points of the different conductive recipes were determined through Melting Point Apparatus. Figure 4 shows the melting behavior of these samples with filler loadings. The methodology adopted is cited as: A small piece was cut from the sample and placed in the heating furnace under a magnifying glass setup under a halogen lamp. A temperature range was set for the experiment. The sample was observed through the magnifying glass for changes. The first point was noted when the sample started to get soft and the final temperature is taken when the sample completely melts. This will give the range of melt for the samples. Here the first reading is mentioned. Copper showed good results so far and iron being at the lowest value. As iron itself is a very good conductor of heat, therefore it might happen that as temperature increased, the interface between iron filler and matrix got hot first and matrix tried to expand. As this temperature is not too much for iron, therefore resultantly the interface was broken down each time and matrix alone showed melting.

\section{Conclusion}

The above work shows that the conductive, thermal and mechanical properties of a particular composite need to be optimized. Although it is possible to improve a specific property by a specific filler, but to have a number of desired properties in a single composite is a 
challenge.

For example, the melting point values of the nickel filled polystyrene were found to be better than the rest but the force at breakage values were higher for iron filled polystyrene. When treated with three different agents, iron filled composites showed improved mechanical and electrical properties. Thus, selection between these two fillers totally depends upon the end property requirements and application conditions.

Further investigation is ongoing in our laboratories to establish correlations among the type of filler, processing temperature and conductivity values.

\section{References}

1) Curodeau, A., et al. (2005), New edm polishing and texturing process with conductive polymer electrodes. Journal of Materials Processing Technology, vol.159(1): 17-26.

2) Checchetto, R., et al. (2009), Hydrogen sorption in metal-polymer composites: The role of interfaces. Journal of Applied Physics

3) Mrozek, R.A., P.J. Cole, and J.L. Lenhart. (2009), Enhanced melt processing of conductive polymer composites through the addition of a low melting eutectic metal.: American Chemical Society

4) Panwar, V., et al. (2009), Study of dielectric properties of styrene-acrylonitrile graphite sheets composites in low and high frequency region. European Polymer Journal, vol.45(6): 17771784.

5) Carson, J.K. and M. Noureldin (2009), Measurements of the thermal diffusivity of linear-medium-density-polyethylene/aluminium composites using a transient. International Communications in Heat and Mass Transfer, vol.36(5): 458-461.

6) Gungor, A. (2007), Mechanical properties of iron powder filled high density polyethylene composites. Materials and Design, vol.28(3): 1027-1030.

7) Hao, X., et al. (2008), Development of the conductive polymer matrix composite with low concentration of the conductive filler. Materials Chemistry and Physics, vol.109(1): 15-19.

8) Nurazreena (2006), Metal filled high density polyethylene composites - electrical and tensile properties. Journal of Thermoplastic Composite Materials, vol.19(4): 413-425.
9) Wycisk, R., R. Pozniak, and A. Pasternak (2002), Conductive polymer materials with low filler content. Journal of Electrostatics, vol.56(1): 5566.

10) Boiteux, G., et al. (2007), From conductive polymer composites with controlled morphology to smart materials. Synthetic Metals, vol.157(24): 1071-1073.

11) Cui, L., et al. (2007), Electrical properties and conductive mechanisms of immiscible polypropylene/novolac blends filled with carbon black. European Polymer Journal, vol.43(12): 5097-5106.

12) Zhang, L.-m. and G.-c. Dai, Mechanical and thermal properties of polypropylene/zno composite. Huadong Ligong Daxue Xиebao, Ziran Kexueban, vol.36(1): 66-72.

13) Chunhui, S., P. Mu, and Y. Runzhang (2008), The effect of particle size gradation of conductive fillers on the conductivity and the flexural strength of composite bipolar plate. International Journal of Hydrogen Energy, vol.33(3): 10351039.

14) Kim, Y.S. (2009), Electrical conductivity of segregated network polymer nanocomposites.

15) Quercia, L., F. Loffredo, and G. Di Francia (2005), Influence of filler dispersion on thin film composites sensing properties. Sensors and Actuators B: Chemical, vol.109(1): 153-158.

16) Abshinova, M.A., et al. (2007), Correlation between the microstructure and the electromagnetic properties of carbonyl iron filled polymer composites. Composites Part A, vol.38(12): 2471-2485.

17) Jiang, G., et al. (2002), Preparation of nickel coated mica as a conductive filler. Composites Part A: Applied Science and Manufacturing, vol.33(5): 745-751.

18) Xingyi, H., et al. (2009), Influence of aluminum nanoparticle surface treatment on the electrical properties of polyethylene composites. Journal of Applied Physics. 
Table 3. Compositions of wax and stearic acid treated iron filler composite samples

\begin{tabular}{|c|c|c|c|c|}
\hline Sr. & $\begin{array}{c}\text { Polystyren } \\
\text { e (weight } \\
\text { No. }\end{array}$ & $\begin{array}{c}\text { Iron } \\
\text { (weight } \\
\text { \%) }\end{array}$ & $\begin{array}{c}\text { Wax } \\
\text { (weight } \\
\text { \%) }\end{array}$ & $\begin{array}{c}\text { Stearic } \\
\text { Acid } \\
\text { (weight } \\
\text { \%) }\end{array}$ \\
\hline 1 & 88 & 10 & 2 & 2 \\
\hline 2 & 86 & 10 & 4 & 4 \\
\hline 3 & 84 & 10 & 6 & 6 \\
\hline 4 & 82 & 10 & 8 & 8 \\
\hline 5 & 80 & 10 & 10 & 10 \\
\hline
\end{tabular}

Table 4. Composition of acetic acid treated iron filler composite samples

\begin{tabular}{|c|c|c|c|}
\hline $\begin{array}{c}\text { Sr. } \\
\text { No. }\end{array}$ & $\begin{array}{c}\text { Polystyrene } \\
\text { (weight \%) }\end{array}$ & $\begin{array}{c}\text { (weight } \\
\text { \%) }\end{array}$ & $\begin{array}{c}\text { Acetic Acid } \\
\text { (weight \%) }\end{array}$ \\
\hline 1 & 89.6 & 10 & 0.4 \\
\hline 2 & 89.2 & 10 & 0.8 \\
\hline 3 & 88.8 & 10 & 1.2 \\
\hline 4 & 88.4 & 10 & 1.6 \\
\hline 5 & 88 & 10 & 2 \\
\hline
\end{tabular}

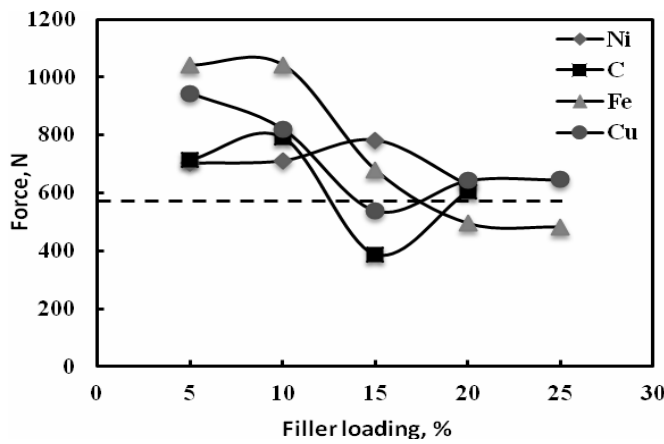

Fig 1. Effect of \% loading of different fillers on ultimate tensile force of the composite samples.

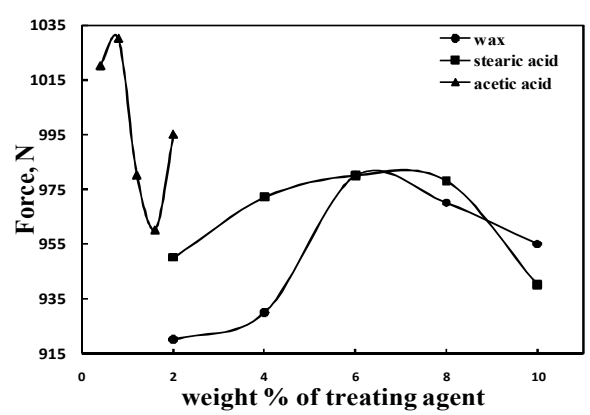

Fig 2. Effect of treating agents on the ultimate tensile force of iron filled composites.

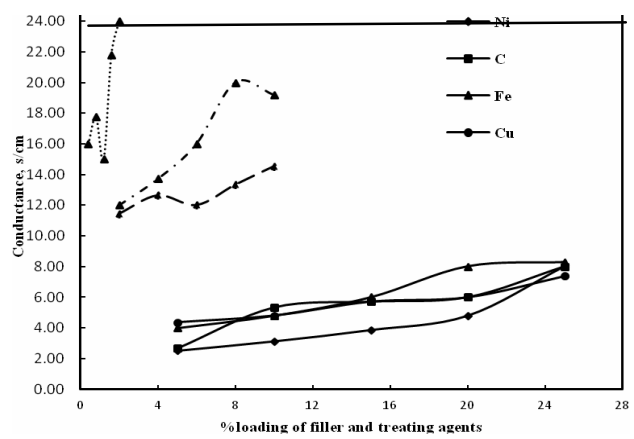

Fig 3. Effect of filler loading on the conductivity of composite samples.

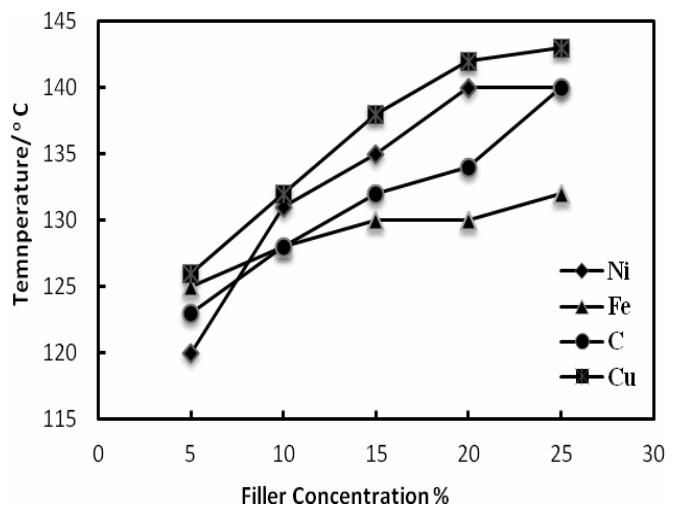

Fig 4. Influence of filler concentration on melting temperature. 